\title{
The effectiveness of removing precursors of chlorinated organic substances in pilot water treatment plant
}

\author{
Matgorzata Wolska ${ }^{1,2,}$, , Stawomir Szerzyna ${ }^{1}$, Justyna Machi $^{1}$, Marek Mołczan ${ }^{1,2}$, \\ Wojciech Adamski ${ }^{1}$, and Jacek Wiśniewski ${ }^{1}$ \\ ${ }^{1}$ Faculty of Environmental Engineering, Wrocław University of Science and Technology, \\ Wyb. Wyspiańskiego 27, 50-370 Wrocław, Poland \\ ${ }^{2}$ Wroclaw Municipal Water and Sewage Company, New Technologies Center, ul. Na Grobli 14/16, \\ 50-421 Wrocław, Poland
}

\begin{abstract}
The presence of organic substances in the water intaken for consumption could be hazardous to human health due to the potential formation of disinfection by-products (TOX). The study were carried out in the pilot surface water treatment system consisting of coagulation, sedimentation, filtration, ozonation, adsorption and disinfection. Due to continuous operation of the system and interference with the parameters of the processes it was possible not only assess the effectiveness of individual water treatment processes in removing TOX, but also on factors participating on the course of unit processes.
\end{abstract}

\section{Introduction}

The creation of oxidation by-products during water treatment is connected with a very large risk to consumer health $[1,2]$. Therefore, studies have been carried out for many years worldwide aiming to identify these oxidation by-products and to determine the factors contributing to the type and amounts of harmful substances created.

Chlorine/sodium hypochlorite is still the most commonly used disinfectant, and therefore it is important to determine the factors contributing to the formation of chlorination by-products, of which the most dangerous are chlorinated organic compounds $[3,4]$. The types of Total Organic Halogens (TOX) created depend above all on the type and amount of organic matter contained in the water undergoing disinfection $[5,6]$. Therefore, effective removal of organic substances, in particular TOX precursors, in processes preceding disinfection is necessary for limiting health hazards.

The amount of chlorinated oxidation products created is decided by the amount of refractive substances in water, i.e. compounds of a complicated molecular structure. As shown by Chu et al. [7] the amount of TOC precursors is proportional to dissolved organic carbon (DOC) in water undergoing treatment, but above all to UV absorbance at wavelengths of $254 \mathrm{~nm}$ and $272 \mathrm{~nm}$. It is also known that organic substances absorbing UV

\footnotetext{
*Corresponding author: malgorzata.wolska@pwr.edu.pl
} 
light are removed during adsorption and coagulation processes [8-11]. However, rarely, and practically never, do these process ensure a complete elimination of the hazards connected with TOX formation. Limiting the amounts of oxidation by-products can be achieved by increasing the effectiveness of complete mineralization of organic substances, which can be obtained by increasing chemical oxidant dosages and increasing the oxidation time, especially when using $\mathrm{ClO}_{2}$ [12]. Results of studies [13, 14] have shown that, in fact, free chlorine reacts slowly with organic substances. In operating water treatment systems, increasing the oxidation time is most often impossible, which is compensated by increasing chemical oxidant dosages. In the case of using free chlorine, and to a lesser degree when using $\mathrm{ClO}_{2}$, the above solution unfortunately results in increasing chloroorganic compound concentrations in water [15-17].

Therefore it is important to maximize organic substance removal in processes preceding disinfection. The aim of this study was determining the effectiveness in removing organic contaminants as potential precursors of chlorinated organic substances in a pilot surface water treatment system and determining the factors contributing to the effectiveness of their removal in unit processes.

\section{Subject and methods of study}

The study was conducted from January to August in two surface water treatment systems (TS - Test System, RS - Reference system), made up of coagulation, sedimentation, filtration, adsorption and disinfection with $\mathrm{pH}$ correction. In the time period preceding study termination, an ozonation process was introduced prior to adsorption. Each of the system operated with a throughput of $3 \mathrm{~m}^{3} / \mathrm{h}$ (fig. 1).

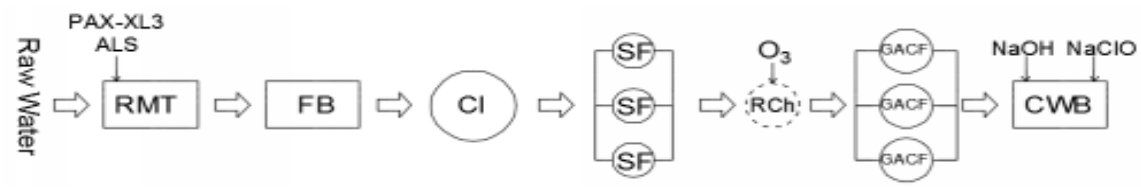

RMT - Rapid Mixing Tank, FB - Flocculation Basin, Cl - Clarifier, SF - Sand Filter, RCh Reaction Chamber, GACF - Granular Activated Carbon Filter, CWB - Clear Water Basin

Fig. 1. Water treatment system schematic.

The coagulation process used PAX-XL3 (from January to April 13) and ALS (from April 13 to August). The coagulant dosage for both treatment systems was in the range of $1.70-3.78 \mathrm{gAl} / \mathrm{m}^{3}$. The sedimentation time for post-coagulation sediments was $2.0 \mathrm{~h}$ and was constant due to the constant water inflow into the system. The water flow speed through the sand bed at the nominal system throughput was $5 \mathrm{~m} / \mathrm{h}$. However, the water adsorption bed contact time was in the range of 13-18 minutes.

The ozonation process was incorporated into the treatment system only during the final days of the study, and therefore it was not possible to determine its effect on the organic substance removal effectiveness. The object of this study were samples of raw water (supplying both systems) and after each unit process from each system. Samples were taken five times per week (Monday to Friday). The water treatment systems were turned off from February to March. For all water samples the following were determined: temperature, $\mathrm{pH}$, conductivity, basicity, turbidity, color in visible light at wavelengths of $340 \mathrm{~nm}$ and 410 $\mathrm{nm}$, UV absorbance at wavelengths of $254 \mathrm{~nm}$ and $272 \mathrm{~nm}$, Total Organic Carbon (TOC) and Dissolved Organic Carbon (DOC) concentrations and dissolved oxygen concentrations. For raw water samples and samples leaving the sedimentation tank the zeta potential was 
determined. Based on the DOC content and $\mathrm{UV}_{254}$ absorbance value the specific ultraviolet absorbance (SUVA) was calculated.

\section{Results and discussion}

During the entire study period the source water contained dissolved oxygen, with its concentration reducing from April so that during the final period of study it amounted to only $33 \%$ of the concentration at the beginning of study, which was directly connected with temperature changes of the source water.

Due to the long study period, the source surface water was characterized by large changes of not only temperature but also content, (tab.1), especially with respect to organic substance content. Among the organic substances in the raw water, the dissolved fraction dominated, which made up $93.7 \%$ to $100 \%$ of total organic carbon. It is precisely these compounds that are precursors to chlorinated disinfection by-products [18], and an evaluation of their removal effectiveness was the essence of this study. Liming of the risk connected with the formation of disinfection by-products (DBPs) is therefore proportional to the reduction in $\mathrm{UV}_{254}$ and $\mathrm{UV}_{272}$, absorbance, which during the study period varied significantly for raw water (tab. 1). As shown by Lee and Westerhoff [19], values of SUVA in source surface water (tab. 1) indicate a low susceptibility of organic substances to removal during the coagulation process.

In spite of this, this process ensured a reduction in total and dissolved organic carbon in the ranges of $2.3-26.4 \%$ and $1.8-26.9 \%$ and also $3.7-27.1 \%$ and $9.2-27.5 \%$ respectively for the reference and test systems.

In general, the coagulation process effectiveness in removing organic substances increased with increases in raw water temperature (fig. 2). The deviation from this relationship in the first study period (From January to April) may have been caused by the use a pre-hydrolized coagulant during this time, whose effectiveness is dependent on water temperature to a much smaller degree. These relationships were similar in both systems.

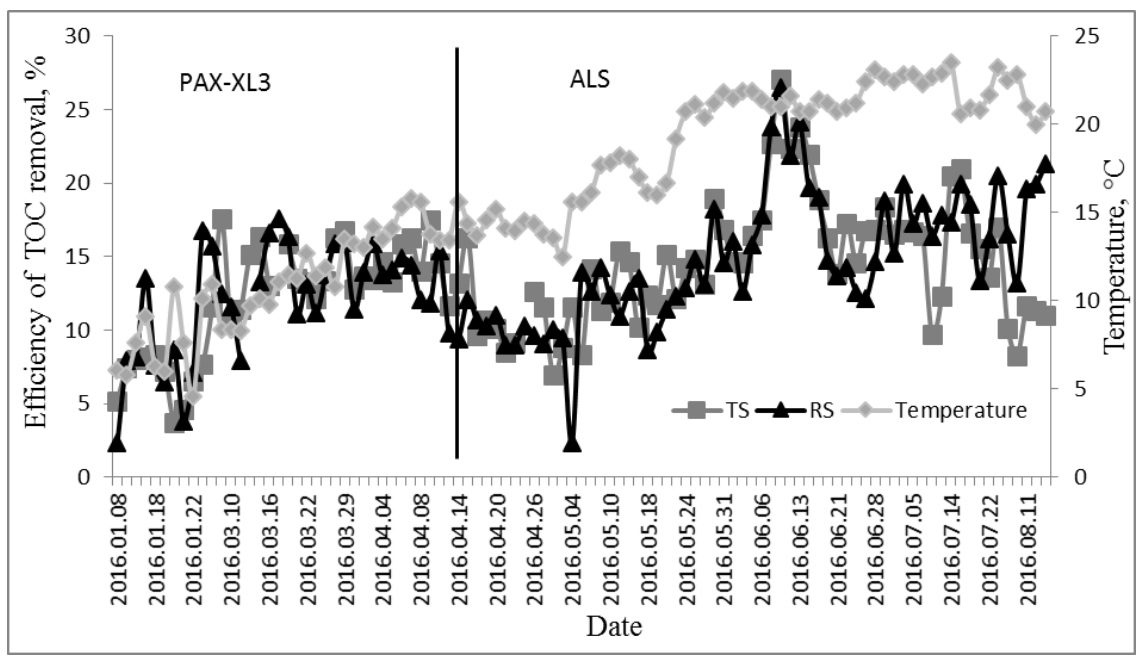

Fig. 2. Variation in Total Organic Carbon removal during coagulation and water temperature.

No unambiguous relationship was found between the organic substance removal effectiveness and the coagulant dosages, regardless of the type of used coagulant. On the 
other hand, the coagulation effectiveness depended on the degree of raw water contamination and increased with increases in this contamination.

Table 1. Ranges of studied water quality indicators.

\begin{tabular}{|c|c|c|c|c|c|c|c|}
\hline \multirow[b]{2}{*}{ Parameter } & \multirow[b]{2}{*}{ RW* } & \multicolumn{3}{|c|}{ Test System (TS) } & \multicolumn{3}{|c|}{ Reference System (RS) } \\
\hline & & $\mathrm{CO}^{*}$ & $\mathbf{S F}^{*}$ & GAC* & $\mathrm{CO}^{*}$ & $\mathrm{SF}^{*}$ & GAC* \\
\hline Temperature, ${ }^{\circ} \mathrm{C}$ & $4.6-23.5$ & $5.2-23.5$ & $5.9-23.6$ & $7.1-23.7$ & $7.9-23.5$ & $8.3-23.5$ & $9.5-23.6$ \\
\hline $\mathrm{pH}$ & $6.78-8.08$ & $6.77-8.06$ & $6.65-8.03$ & $6.64-7.93$ & $6.63-8.02$ & $6.43-7.91$ & $6.32-7.92$ \\
\hline $\begin{array}{c}\text { Conductivity, } \\
\mu \mathrm{S} / \mathrm{cm}\end{array}$ & 393 & 6 & 5 & 7 & $397-$ & 9 & 0 \\
\hline Basicity, val $/ \mathrm{m}^{3}$ & $2.16-3.19$ & $2.02-2.96$ & $2.01-2.97$ & $2.01-2.93$ & $1.97-3.00$ & $1.91-2.95$ & $1.93-2.95$ \\
\hline Turbidity, NTU & $3.7-28.5$ & $0.3-14.3$ & $0.0-3.4$ & $0.0-0.6$ & $0.4-8.4$ & $0.1-0.5$ & $0.0-0.3$ \\
\hline UV $254, \mathrm{~m}^{-1}$ & $5.08-14.76$ & $2.01-13.55$ & $1.21-11.98$ & $2.10-8.04$ & $1.96-10.26$ & $1.24-9.76$ & $2.47-7.32$ \\
\hline UV $272, \mathrm{~m}^{-1}$ & $5.04-11.95$ & $2.51-10.95$ & $1.83-9.68$ & $0.28-6.39$ & $2.46-8.26$ & $1.85-7.83$ & $0.30-5.76$ \\
\hline Color $340, \mathrm{~g} / \mathrm{m}^{3}$ & 5.74-14.46 & $3.20-12.75$ & $2.89-11.08$ & $0.57-6.20$ & $5.25-9.74$ & $4.55-8.06$ & $0.43-5.21$ \\
\hline Color $410, \mathrm{~g} / \mathrm{m}^{3}$ & $8.05-24.11$ & $2.52-20.24$ & $2.74-18.31$ & $0.15-8.18$ & $2.46-14.61$ & $1.12-10.96$ & $0.95-6.24$ \\
\hline Oxygen, $\mathrm{gO}_{2} / \mathrm{m}^{3}$ & $4.91-12.21$ & \begin{tabular}{|l|}
$7.91-12.23$ \\
\end{tabular} & $7.17-12.1$ & $5.37-12.7$ & $7.89-11.55$ & $7.14-11.19$ & $5.58-14.28$ \\
\hline $\mathrm{TOC}, \mathrm{gC} / \mathrm{m}^{3}$ & $3.23-5.90$ & $2.71-5.69$ & $2.69-5.22$ & $2.01-4.05$ & $3.34-5.04$ & $2.83-4.56$ & $2.35-3.85$ \\
\hline DOC, $\mathrm{gC} / \mathrm{m}^{3}$ & $3.34-5.62$ & $2.42-5.45$ & $2.54-5.03$ & $1.92-4.01$ & $3.14-4.68$ & $2.78-4.46$ & $2.31-3.79$ \\
\hline Zeta potential, $\mathrm{mV}$ & $-15.10--7.85$ & $-13.50--6.27$ & - & - & $-12.80--6.63$ & - & - \\
\hline $\mathrm{SUVA}, \mathrm{m}^{3} / \mathrm{gC} \cdot \mathrm{m}$ & $1.27-2.69$ & $0.63-2.49$ & $0.43-2.38$ & $0.89-2.07$ & $0.62-2.29$ & $0.44-2.28$ & $0.92-1.95$ \\
\hline
\end{tabular}

* RW - raw water, CO - outflow from the settling tank, SF - outflow from sand filters, $\mathrm{GAC}$ - outflow from carbon filter

Among the dissolved organic substances removed during the coagulation process, chlorinated organic substance precursors dominated, which is shown by effectivenesses in decreasing $\mathrm{UV}_{254}$ and $\mathrm{UV}_{272}$ absorbance in the ranges of $3.6-61.8 \%$ and $3.9-51.2 \%$ for $\mathrm{RS}$ and $0.9-60.3 \%$ and $0.8-50.2 \%$ for TS. The effectiveness in reducing the values of these parameters were similar to each other, which is connected with similar properties of substances absorbing UV radiation at the analyzed wavelengths. On the other hand, differences in obtained effectivenesses between the two treatment systems should be explained by differences in hydraulic flow conditions between subsequent devices for coagulation and sedimentation. The effectiveness of reducing UV absorbance during coagulation depended on the values of these parameters in source water. The effectiveness in removing DOC was proportional to decreases in UV absorbance (fig. 3).

Due to reductions in refractive substances as evaluated by $\mathrm{UV}_{254}$, a $14.2 \%$ and $14.7 \%$ reduction in specific absorption occurred respectively for the reference and test systems.

A consequence of removing organic substances was a decrease in the coagulated water color intensity. The study evaluated the reduction in color intensity which was determined for absorbance at two wavelengths of $340 \mathrm{~nm}$ and $410 \mathrm{~nm}$. The coagulation process provided a very effective reduction of color intensity at both wavelengths. The greater effectiveness found for $410 \mathrm{~nm}$ is due to the properties of substances present in water (SUVA values). 


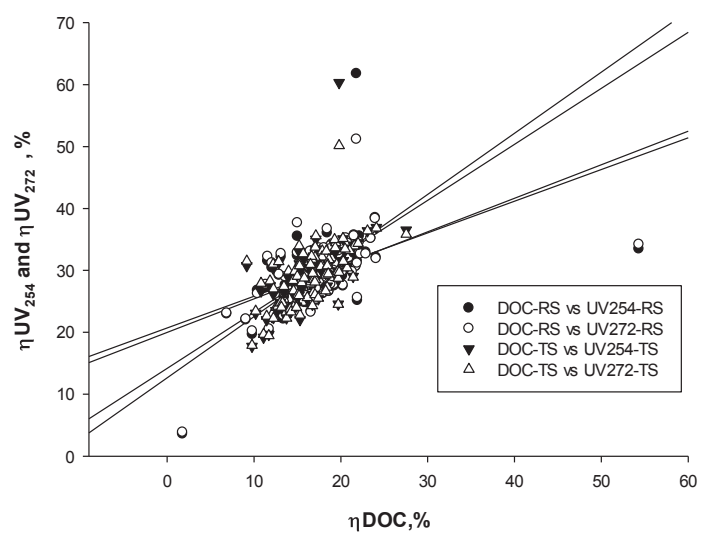

Fig. 3. Reduction in UV absorbance as a function of DOC removal.

The zeta potential for post-coagulation water samples was lower than that found for source water, however no transition of this potential through the isoelectric point was detected. This may point to the possibility of increasing coagulation effectiveness by a significant increase in coagulant dosage, but this is not economically justifiable.

Water coming into GAC beds was characterized by low SUVA values (tab. 1). The effectiveness in removing dissolved organic carbon was in the ranges of $7.3-28.0 \%$ and $4.0-35.4 \%$ for the reference and test systems respectively. No clear impact of the temperature of treated water on DOC removal effectiveness was found, with the highest effectiveness found mid-January (fig. 4).

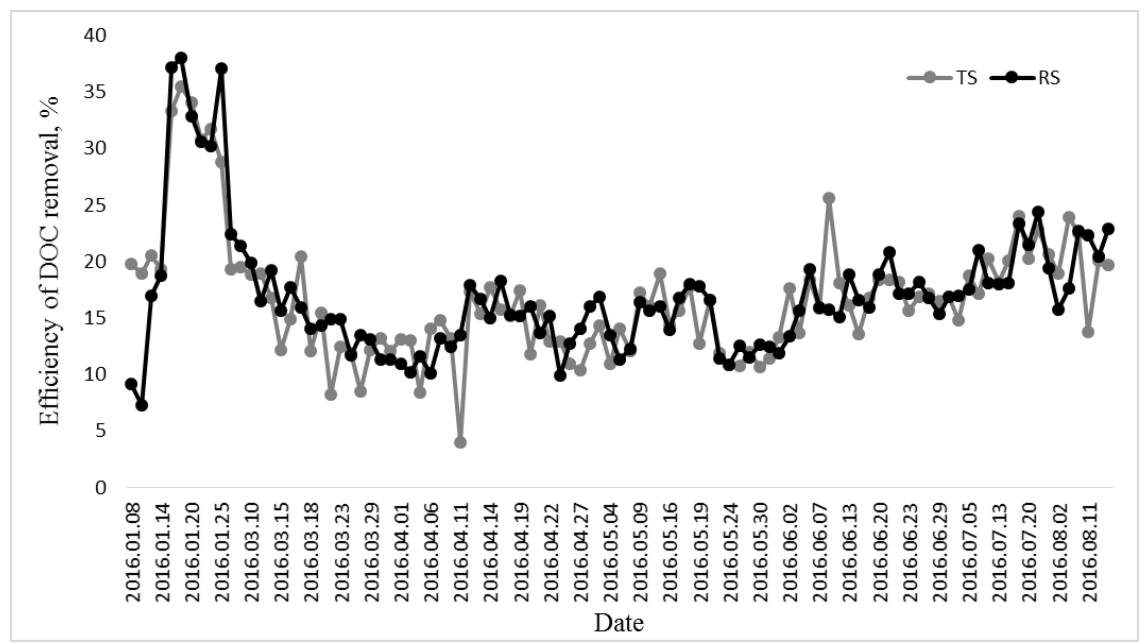

Fig. 4. DOC removal effectiveness during the absorption process. 
The reduction in DOC was accompanied by a decrease in ultraviolet absorbance $\left(\mathrm{UV}_{254}\right)$, and therefore by a decrease in chlorinated organic substance precursors in the range of $18.3-54.3 \%$ in the test system and $19.5-54.2 \%$ in the reference system. The resulting effectiveness is comparable to that found during the coagulation process, which may point to the fact that large molecular mass compounds were removed during coagulation, while medium molecular mass compounds were removed during adsorption [21], with compounds absorbing UV light dominating the fraction removed in both processes.

Adsorption also provided for a reduction in $\mathrm{UV}_{272}$, whose effectiveness was proportional to the reduction in color intensity at $340 \mathrm{~nm}$, and to a lesser degree at $410 \mathrm{~nm}$ (fig. 5). An analogous relationship was found $\mathrm{UV}_{254}$ absorbance.

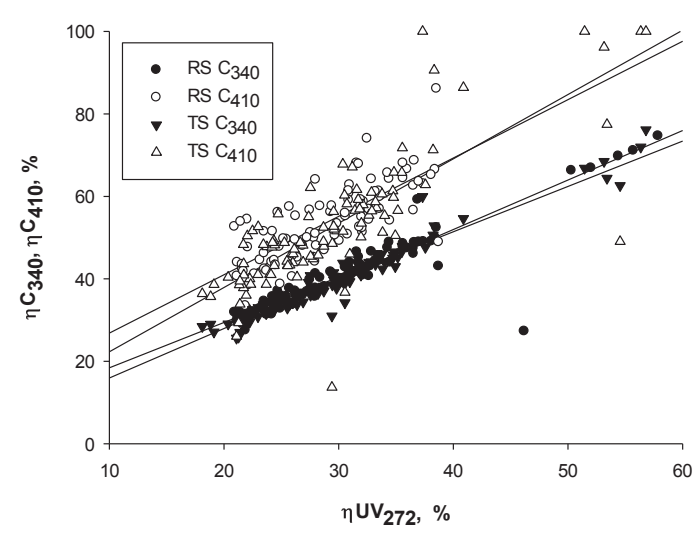

Fig. 5. Reduction in color intensity ( $340 \mathrm{~nm}$ and $410 \mathrm{~nm}$ ) as a function of effectiveness in removing organic substances exhibiting absorbance at $272 \mathrm{~nm}$.

No unambiguous impact of activated carbon-water contact time on the effectiveness of removing chlorinated organic compound precursors was found. This must be explained by very small differences in the time of water flow through the bed, because, as Esa et al [22] found, the greatest degree in removing organic substances takes place at contact times 20 minutes, with significant changes being observed in the first 20 minutes.

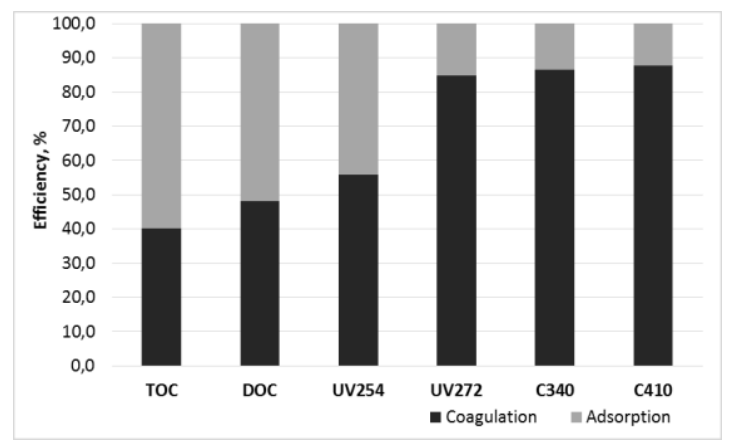

Fig. 6. Average effectiveness in reducing water organic contamination indicators (reference system). 
A consequence of reduction in absorbance were further decreases in UV specific absorbance, which in water after adsorption amount to $0.92-1.95 \mathrm{~m} 3 / \mathrm{gC} \cdot \mathrm{m}$ and $0.89-2.07 \mathrm{~m}^{3} / \mathrm{gC} \cdot \mathrm{m}$ respectively for reference and test systems. The reduction in UV absorbance reduces hazards to human health connected with the formation of disinfection by-products. The effectiveness in removing organic substances, and in particular chlorinated organic substance precursors, was influenced by these two described processes. However, no significant effect of filtration through a sand bed on organic substance content was found. Coagulation contributed mainly to removal of colored organic substances and reduction in $\mathrm{UV}_{272}$, and absorption to reductions in $\mathrm{UV}_{254}$ absorbance. Ultimately, the adsorption process has a greater effect on reducing total and dissolved organic carbon (fig. 6).Water undergoing disinfection still contained precursors of chlorinated organic substances, however their concentrations were significantly lower than those in source water, and exhibited a lower variability with time. The chlorinated organic substance precursor content in water undergoing disinfection dependent above all on the source water quality (fig. 7). However, no unambiguous effect was found of source water temperature on $\mathrm{UV}_{254}$ and $\mathrm{UV}_{272}$ absorbance.

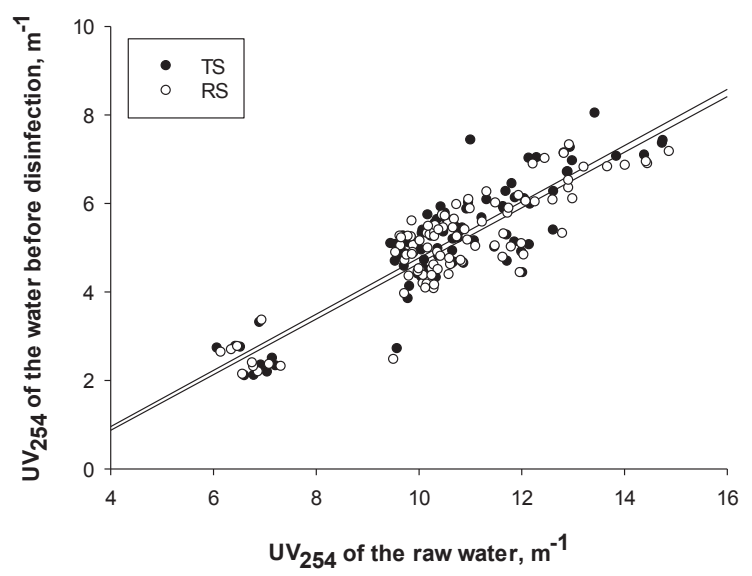

Fig. 7. Relationship between chlorinated organic substance precursor content in raw water and water before disinfection.

\section{Summary}

The study showed that:

- Chlorinated organic substance precursors, evaluated as content of substances exhibiting ultraviolet absorbance, are most effectively removed in coagulation and adsorption processes, and their effectiveness depends on the source water quality.

- Reducing the effect of source water temperature on the effectiveness of removing chlorinated organic substance precursors during the coagulation process was achieved by the use of a pre-hydrolyzed coagulant.

- Coagulation influenced the removal of colored organic substances to a larger degree than adsorption, which ensured a greater effectiveness in removing total organic carbon.

- The water-adsorption bed contact time had no effect on TOX precursor removal effectiveness. 
- The effectiveness in removing chlorinated organic substance precursors in the water treatment system was decided by the source water quality.

This publication was made possible by the National Center for Research and Development grant (PBS3/B9/44/2015) "Research on effectiveness of new water treatment technology as a step towards a shift in thinking about water utility sector" (WODTECH), and thanks to involvement of both project consortium members (Wrockaw Municipal Waterworks and Drainage Company and Wroctaw University of Science and Technology).

\section{References}

1. Y-L. Lin, P-Ch. Chiang, E.E. Chang, J. Hazard. Mater. 146, 20-29 (2007)

2. B. Kalajdžić, M. Habuda-Stanić, Ž. Romić, M. Kuleš, Global Nest J. 15, 13-20 (2013)

3. S.D. Richardson, D.M. DeMarini, M. Kogevinas, P. Fernandez, E. Marco, C. Lourencetti, R. Marcos, Environ. Health Persp. 118, 11, 1523 (2010)

4. J. Fang, J. Ma, X. Yang, C. Shang, Water Res. 44, 6, 1934-1940 (2010)

5. M.J. Plewa, J.E. Simmons, S.D. Richardson, E.D. Wagner, Environ. Mol. Mutagen. 51, 8-9, 871-878 (2010)

6. T. Bond, J. Huang, M.R. Templeton, N. Graham, Water Res. 45, 15, 4341-4354 (2011)

7. W. Chu, N. Gao, D. Yin, Y. Deng, M.R. Templeton, Chemosphere 86, 11, 1087-1091 (2001)

8. A. Matilainen, M. Vepsäläinen, M. Sillanpää, Adv. Colloid Interfac. 159, 2, 189-197 (2010)

9. W. Xu, B. Gao, Y. Wang, Z. Yang, X. Bo, Chem. Eng. J. 171, 3, 926-934 (2011)

10. J. Altmann, A.S. Ruhl, F. Zietzschmann, M. Jekel, Water Res. 55, 185-193 (2001)

11. K. Yapsakli, F. Çeçen, Process Biochem. 45, 3, 355-362 (2010)

12. A. Dąbrowska J. Świetlik J. Nawrocki, Water Res. 37, 5, 1161-1169 (2003)

13. S. Fass, J.C. Block, M. Boualam, V. Gauthier, D. Gatel, J. Cavard S. Benabdallah, V. Lahoussine, Water Res. 37, 3, 493-500 (2003)

14. G.V. Korshin, W.W. Wu, M.M. Benjamin, O. Hemingway, Water Res. 36, 13, 3273-3282 (2002)

15. D.A. Reckhow, P.C. Singer, R.L. Malcolm, Environ. Sci. Technol. 24, 11, 655-1664 (1990)

16. C.M.M. Bougeard, E.H. Goslan, B. Jefferson, S.A. Parsons, Water Res. 44, 4, 729-740 (2010)

17. H. Gallard, U. Von Gunten, Water Res. 36, 1, 65-74 (2002)

18. G.V. Korshin, W.W. Wu, M. M. Benjamin, O, Hemingway, Water Res. 36, 13, 3273-3282 (2002)

19. W. Lee, P. Westerhoff, Water Res. 40, 20, 3767-3774 (2006)

20. S.K. Bekaroglu, N. O. Yigit, T. Karanfil, M. Kitis, J. Hazard. Mater. 183, 1, 389-394 (2010)

21. C. Guigui, J.C. Rouch, L. Durand-Bourlier, V. Bonnelye, P. Aptel, Desalination 147, $1-3,95-100$ (2002)

22. E.S. Melin, H. Ødegaard, Water Res. 34, 18, 2001 (2000) 